Document downloaded from:

http://hdl.handle.net/10251/93322

This paper must be cited as:

Manuel Pineda-Sanchez; Riera-Guasp, M.; J. Antonino-Daviu; José Roger-Folch; Juan Perez-Cruz; Rubén Puche-Panadero (2010). Diagnosis of Induction Motor Faults in the Fractional Fourier Domain. IEEE Transactions on Instrumentation and Measurement. 59(8):2065-2075. doi:10.1109/TIM.2009.2031835

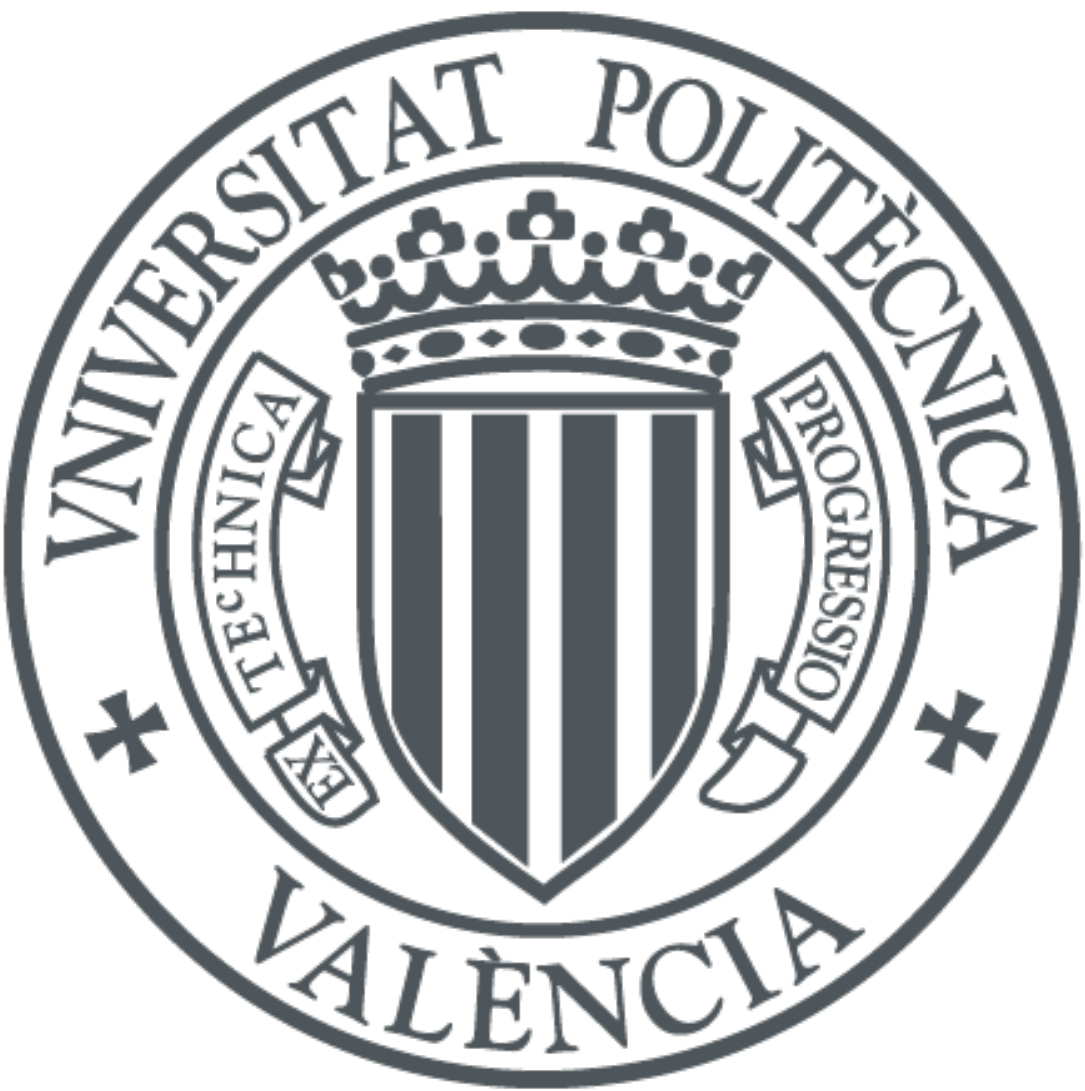

The final publication is available at

http://doi.org/10.1109/TIM.2009.2031835

Copyright Institute of Electrical and Electronics Engineers

Additional Information 


\title{
Diagnosis of Induction Motor Faults in the Fractional Fourier Domain
}

\author{
Manuel Pineda-Sanchez, Member, IEEE, M. Riera-Guasp, Member, IEEE, Jose A. Antonino-Daviu, Member, IEEE, \\ J. Roger-Folch, Member, IEEE, J. Perez-Cruz, Member, IEEE, and R. Puche-Panadero, Member, IEEE
}

\begin{abstract}
Motor current signature analysis (MCSA) is a well-established method for the diagnosis of induction motor faults. It is based on the analysis of the spectral content of a motor current, which is sampled while a motor runs in steady state, to detect the harmonic components that characterize each type of fault. The Fourier transform (FT) plays a prominent role as a tool for identifying these spectral components. Recently, MCSA has also been applied during the transient regime (TMCSA) using the whole transient speed range to create a unique stamp of each harmonic as it evolves in the time-frequency plane. This method greatly enhances the reliability of the diagnostic process compared with the traditional method, which relies on spectral analysis at a single speed. However, the FT cannot be used in this case because the fault harmonics are not stationary signals. This paper proposes the use of the fractional FT (FrFT) instead of the FT to perform TMCSA. This paper also proposes the optimization of the FrFT to generate a spectrum where the frequency-varying fault harmonics appear as single spectral lines and, therefore, facilitate the diagnostic process. A discrete wavelet transform (DWT) is used as a conditioning tool to filter the motor current prior to its processing by the FrFT. Experimental results that are obtained with a 1.1-kW three-phase squirrel-cage induction motor with broken bars are presented to validate the proposed method.
\end{abstract}

Index Terms-Failure analysis, Fourier transforms (FTs), induction motors, wavelet transforms (WTs), time-frequency analysis.

\section{INTRODUCTION}

$\mathbf{M}$ OTOR current signature analysis (MCSA) is a wellestablished [1]-[3] and reliable methodology for detecting motor failures. It is noninvasive; various stator and rotor faults can be detected simultaneously; and it is simple to apply because only a current transformer is needed to capture the motor current. Each type of fault produces oscillations in the motor current whose characteristic frequencies have been estab-

Manuscript received March 2, 2009; revised August 15, 2009; accepted August 5, 2009. This work was supported by the European Community's Seventh Framework Program FP7/2007-2013 under Grant Agreement 224233 (Research Project PRODI "Power Plant Robustification Based on Fault Detection and Isolation Algorithms"). The Associate Editor coordinating the review process for this paper was Dr. Subhas Mukhopadhyay.

The authors are with the Department of Electrical Engineering, Universidad Politécnica de Valencia, 46022 Valencia, Spain (e-mail: mpineda@die.upv.es; mriera@die.upv.es; joanda@die.upv.es; jroger@die.upv.es; juperez@die.upv. es; rupucpa@die.upv.es).

Color versions of one or more of the figures in this paper are available online at http://ieeexplore.ieee.org.

Digital Object Identifier 10.1109/TIM.2009.2031835

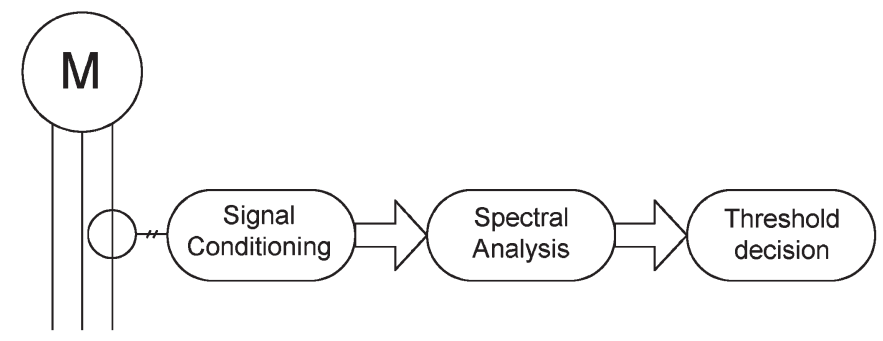

Fig. 1. MCSA diagnostic system.

lished theoretically. For example, rotor bar breakages generate oscillations of frequency $f_{b}$, which is given by

$$
f_{b}(s)=(k / p(1-s) \pm s) f_{1}, \quad \text { with } k / p=1,3,5 \ldots
$$

where $f_{1}$ is the $50 / 60-\mathrm{Hz}$ power supply frequency, $s$ is the rotor slip, and $p$ is the number of pole pairs in the machine.

Mixed eccentricity generates harmonics with frequencies

$$
\begin{aligned}
f_{\text {ecc }}(s) & =\left|f_{1} \pm k \cdot f_{r}\right| \\
& =\left|f_{1} \pm k \cdot(1-s) f_{1} / p\right|, \quad \text { with } k=1,2, \ldots
\end{aligned}
$$

where $f_{r}$ is the frequency corresponding to the mechanical speed of the rotor. Other faults such as stator short circuits, bearing failures, etc., also generate current harmonics with characteristic frequencies that are analogous to (1) and (2). This way, a spectral analysis of a single-phase stator current, which is sampled while the motor is operating in steady state at a given slip $s$, can reveal the presence of these faults. Fig. 1 shows a schematic diagram of an MCSA diagnostic system setup.

In MCSA, the signal conditioning stage may include windowing [4], filtering, frequency displacement [5], elimination of negative frequencies [6], etc. Spectral analysis may be performed with a variety of mathematical tools, such as the Fourier transform (FT) [7]-[10], multiple signal classification [8], maximum covariance methods [11], [12], and others [13]. Finally, a threshold level is established that is based on either the amplitude [7], [14] or the phase of the characteristic fault harmonics, as given in (1) and (2), to diagnose the presence or the absence of a fault.

Transient MCSA (TMCSA) relies on the same fault-related frequencies that are given by (1) and (2); however, instead of trying to detect the frequencies at a single slip, the goal 


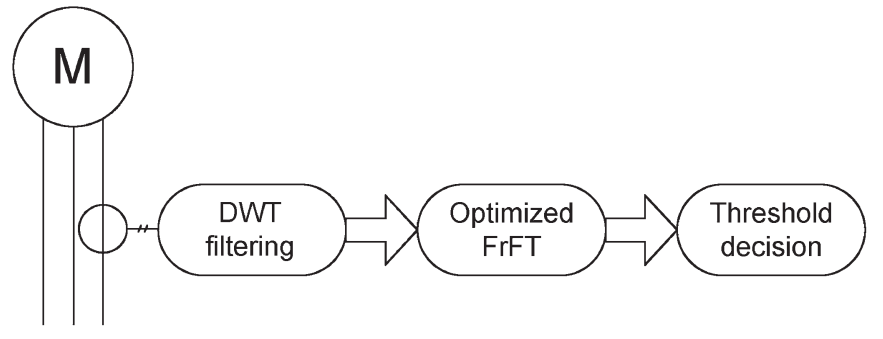

Fig. 2. TMCSA diagnostic system proposed in this paper.

is to identify their variation as a function of the slip during the speed transient. This function is only linear, as stated in (1) and (2).

In TMCSA, the same steps depicted in Fig. 1 are followed but using tools that are specifically designed for the analysis of nonstationary signals. Signal conditioning can be performed with wavelet transforms (WTs) [15]-[18], empirical mode decomposition [19]-[21], time-varying filters [22], etc. Spectral analysis is carried out in the time-frequency plane with linear transforms, such as the short-time FT [23] and the WT [24][34], or quadratic transforms, such as the Wigner-Ville distribution (WVD) [35]-[37]. In [38], an approach based on a combined wavelet and Fourier transformation is proposed, and [39] presents a novel time-domain method for the extraction of sinusoidal signals that are polluted by noise. Despite offering some advantages, TMCSA presents difficulties for its industrial implementation. This is because the specification of threshold values is more complicated in TMCSA than in traditional MCSA due to the added dimension of time. Numerical indicators that are computed from the wavelet coefficients or the energy bands have been proposed; however, the definition of adequate threshold indicators in TMCSA remains an open research field. New tools for processing transient current signals are needed because traditional Fourier-based techniques are not valid for nonstationary signals. This paper addresses both difficulties and proposes a new schema to perform TMCSA, which is analogous to the schema depicted in Fig. 1 (see also Fig. 2).

The new schema (Fig. 2) is composed of a filtering stage of the transient current via discrete WT (DWT), the generation of a spectrum of the filtered current using the fractional FT (FrFT), and a simple threshold stage based on the magnitude of the obtained spectral lines as in standard MCSA. We believe that this is the first time that the FrFT, which is used in the fields of radar, optics, and acoustics for target identification, has been applied in the field of machine diagnosis. Being the transient counterpart of the FT, the use of the FrFT also facilitates the dissemination of TMCSA techniques among the electrical machines community.

The structure of this paper is as follows. In Section II, the left-side harmonic during a startup transient (LSHst) is characterized in the time-frequency domain. In Section III, the theoretical basis of the FrFT is presented, and it is applied and optimized for the detection of the LSHst. Section IV applies the proposed method to the analysis of two experimental $1.1-\mathrm{kW}$ three-phase motors: one with a broken bar and the other one in healthy condition. Section V presents the conclusions.

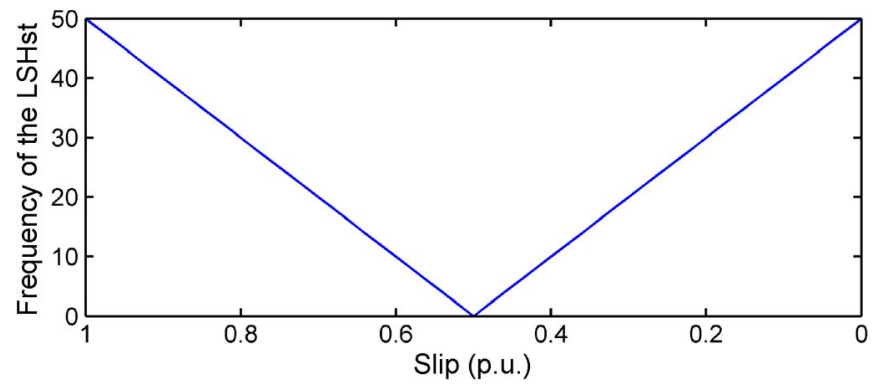

Fig. 3. Evolution of the frequency of the LSHst as a function of the rotor slip.

\section{Time-Frequency Characterization of Fault Harmonics DURING a SPEED TRANSIENT}

In classical MCSA, fault harmonics are characterized by their spectral lines in the frequency Fourier domain, obtained from (1) or (2) for a given slip. In transient MCSA, this approach is no longer valid: The frequency-time domain is needed to represent the harmonic evolution because of the dependence of the harmonic frequency on the slip during the transient.

\section{A. Time Evolution of the Left-Side Harmonic in a Motor With Broken Bars During the Startup Transient}

As an example, an analysis is made of the evolution during the startup transient of the left-side harmonic, which is generated by a broken bar fault. The frequency of this harmonic corresponds to the lowest order in (1), i.e.,

$$
f_{\mathrm{LSH}}(s)=\left|f_{1}(1-2 s)\right|
$$

which is simply a straight line (Fig. 3) of the absolute slope

$$
\left|\frac{d\left(f_{\mathrm{LSH}}(s)\right)}{d s}\right|=2 f_{1} \text {. }
$$

In the case of a supply frequency $f_{1}=50 \mathrm{~Hz}$, this slope has a constant value of

$$
\left|\frac{d\left(f_{\mathrm{LSH}}(s)\right)}{d s}\right|=2 f_{1}=2 \cdot 50=100 \mathrm{~Hz} / \text { slip unit. }
$$

The evolution of the LSHst has been analyzed by Riera-Guasp et al. [40]. Fig. 4 shows this evolution during a startup transient of a simulated machine, only considering the fundamental space harmonic of its windings, and sampled during $2 \mathrm{~s}$ at $500 \mathrm{~Hz}$. Both the speed and the slip of the motor during the transient are shown in Fig. 4. The slip has been computed as

$$
s(t)=\left(1500-n_{r}(t)\right) / 1500
$$

where $n_{r}$ is the motor speed in revolutions per minute.

For not too fast startups, once the electromagnetic transient finishes, it can be assumed that the machine accelerates following a succession of stationary regimes with increasing speeds. Under such conditions, the left-sideband harmonic basically 

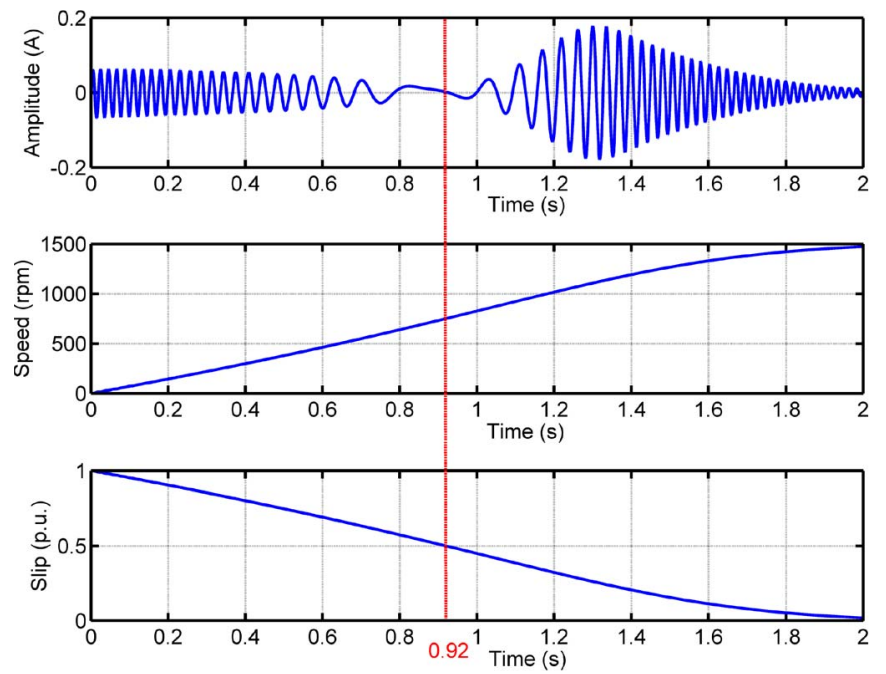

Fig. 4. Amplitude of the (top) LSHst, (middle) motor speed, and (bottom) motor slip during the startup transient of a simulated motor. The vertical line corresponds to the time when the slip $s=0.5$ is reached.

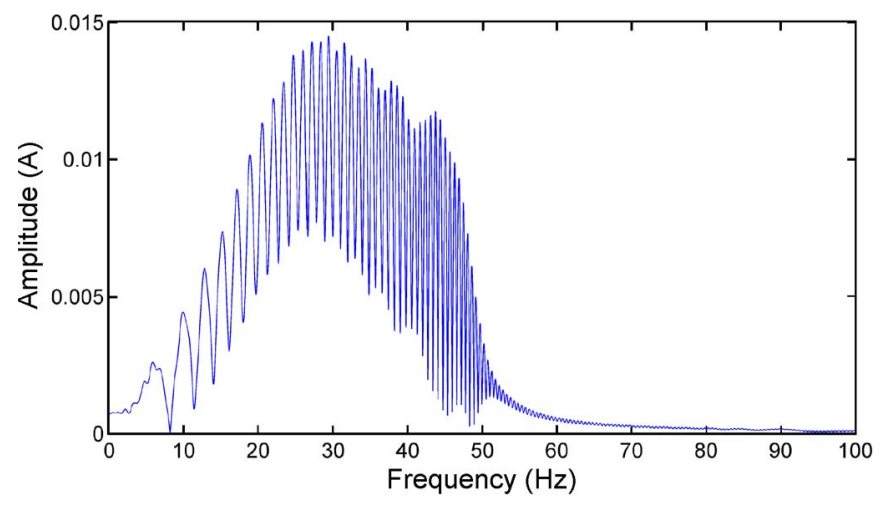

Fig. 5. Fourier spectrum of the LSHst.

evolves as a sinusoidal wave whose frequency and amplitude continuously vary and follow characteristic patterns. Two types of patterns can be identified in Fig. 4: 1) a frequency-time pattern and 2) an amplitude-time pattern.

The frequency of the LSHst continuously decreases from the supply frequency $(50 / 60 \mathrm{~Hz})$ when the machine is connected $(t=0)$, becoming null when the rotor speed is equal to half of the synchronous speed $\Omega s / 2(t \approx 0.92 \mathrm{~s}$; see Fig. 4 , vertical line). From this point, the frequency of the sideband component again increases, keeping a constant value when the stationary regime is reached.

The amplitude of the LSHst also shows a characteristic evolution. Initially, from $t=0$, the amplitude decreases, becoming null when the rotor speed is equal to half of the synchronous speed $\Omega s / 2$ (slip $s=0.5$ ). During the second half of the startup $(t>0.92 \mathrm{~s})$, the LSHst amplitude initially grows, reaching a maximum that exceeds the amplitudes that are reached during the first half of the startup.

The Fourier spectrum of the LSHst, as shown in Fig. 5, is unable to capture these patterns. Due to the nonstationary character of the signal, its energy spreads over the full range of $0-$ to $50-\mathrm{Hz}$ frequencies, and there is no distinct peak in the spectrum that marks the presence of the fault harmonic.

\section{B. Representation of the LSHst in the Time-Frequency Plane}

The WVD is a quadratic transform that is able to generate a time-frequency representation of the energy of a signal $x(t)$. It is given by [35]

$$
W V_{x}(t, f)=\int_{-\infty}^{+\infty} x^{*}\left(t-\frac{\tau}{2}\right) x\left(t+\frac{\tau}{2}\right) e^{-j 2 \pi f \tau} d \tau .
$$

One of the properties of the WVD is that it satisfies the marginals; that is, the energy spectral density (ESD) and the instantaneous power of the signal can be obtained as the marginal distributions of $W V_{x}$, i.e.,

$$
\begin{aligned}
|X(f)|^{2} & =\int W V_{x}(t, f) d t \quad \text { frequency marginal } \\
|x(t)|^{2} & =\int W V_{x}(t, f) d f \quad \text { time marginal }
\end{aligned}
$$

where $X(f)$ is the FT of $x(t)$. The projection of the WVD of a signal on the frequency axis (8) gives the ESD of the signal, and its projection on the time axis (9) gives the instantaneous power of the signal. In addition, we have

$$
\iint W V_{x}(t, f) d t d f=\text { Energy of } x(t) .
$$

The WVD of the LSHst, along with its marginals, is represented in Fig. 6. The time marginal in this figure has been replaced with the representation of the signal in the time domain for clarity purposes.

The time-frequency representation given in Fig. 6 is visually insightful and reproduces the aforementioned frequency and amplitude evolution patterns of the LSHst. There are two branches of linearly varying frequency, as shown in Fig. 3. However, the frequency marginal (8) does not reveal any distinct peak upon which a threshold value can be established to diagnose the fault. Nevertheless, an inspection of Fig. 6 suggests a method to generate a spectrum exhibiting such a peak, namely, if the whole transform is rotated, so that any of the two branches of the representation becomes horizontally aligned, then the marginal (8) will show a sharp peak at the vertical position of this branch. Fig. 7 shows the result of such a rotation. This way, the most energetic branch becomes horizontally aligned.

The described method, although effective, is cumbersome. First, the WVD of the LSHst, which is a full 2-D time-frequency distribution, must be computed. Second, the whole transform must be rotated in the time-frequency plane. Finally, the spectrum must be obtained via the frequency marginal of the rotated transform. However, there is a shortcut for generating this final spectrum by applying a single transform to the time signal - the FrFT. In Section III, its theoretical principles are briefly discussed, and it is used to detect the presence of the LSHst in a motor with broken bars.

\section{FrFT}

The FrFT, which was first introduced in [41] and [42], is a generalization of the FT [43]. It has extensively been applied in 


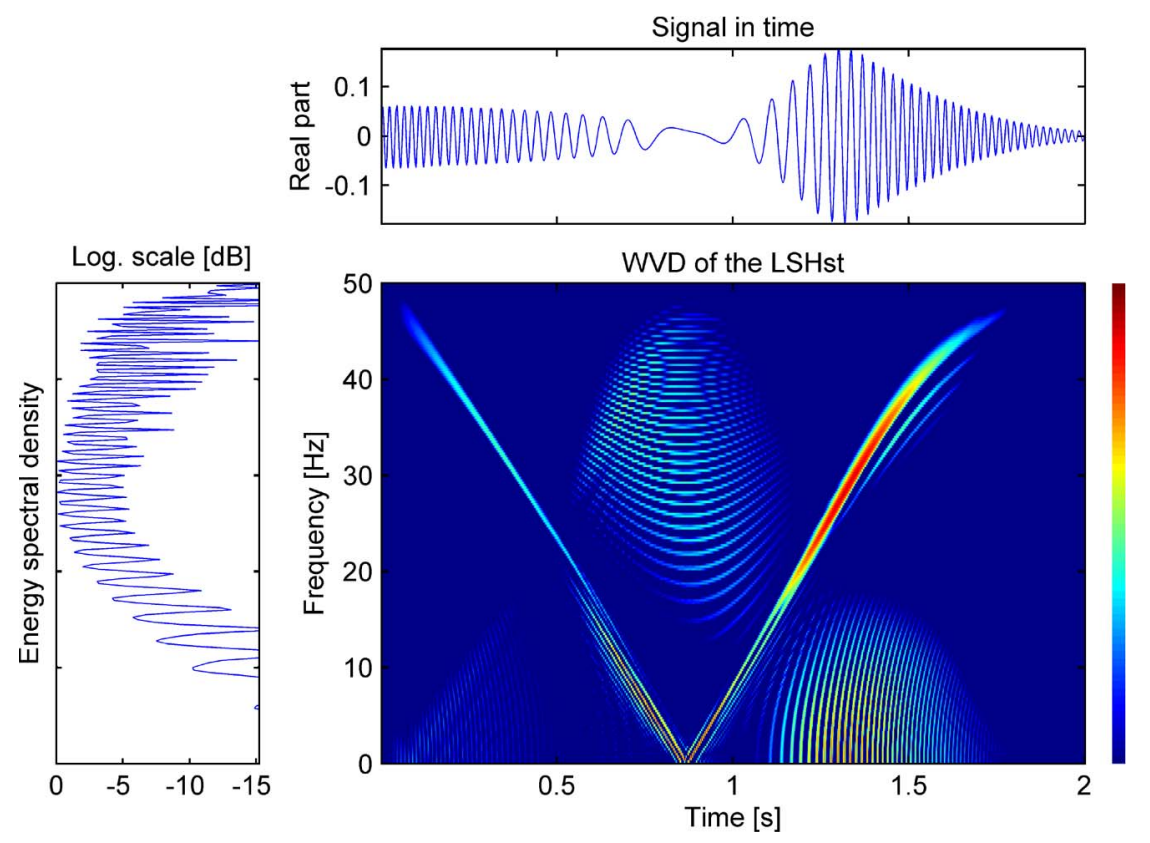

Fig. 6. WVD of the LSHst, with the (left) frequency marginal and (top) signal in the time domain.
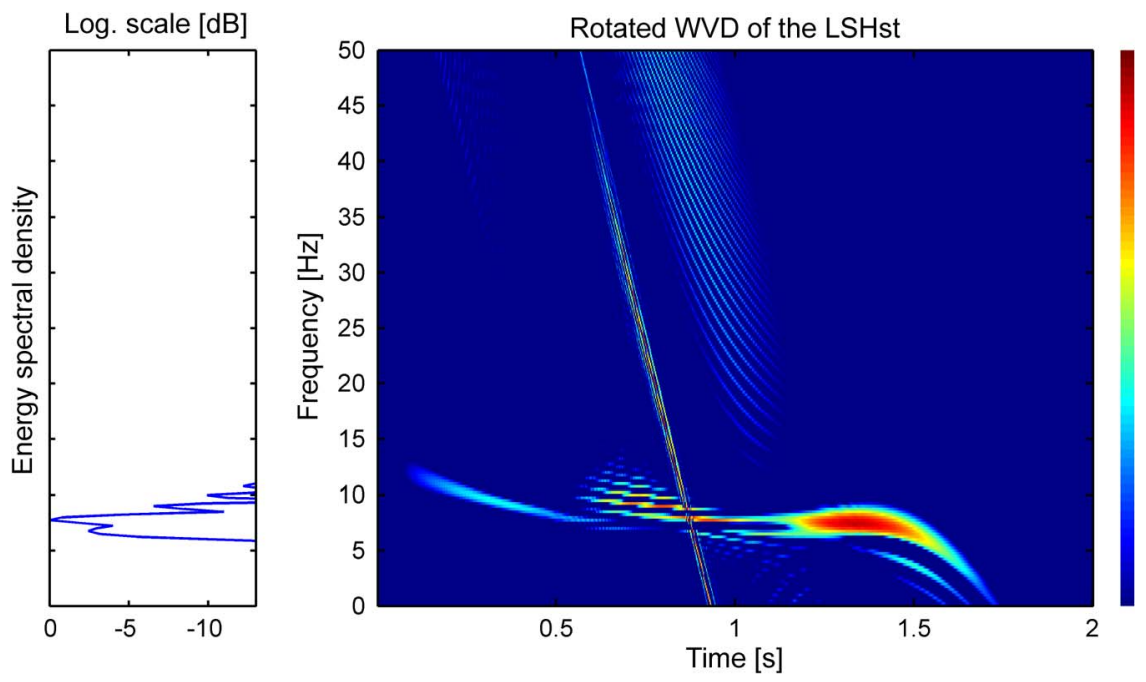

Fig. 7. Rotated WVD of the LSHst, with the frequency marginal showing a peak that reveals the presence of the fault harmonic.

the fields of communications [44], optical systems [45], radar identification [46], and signal filtering [47]. Its properties and connections with time-frequency signal representations have been analyzed in [48].

The FrFT with an angle $\alpha$ of a signal $x(t)$, which is denoted $F_{x}^{\alpha}(u)$, is defined by [49]

$$
F_{x}^{\alpha}(u)=\int_{-\infty}^{\infty} x(t) K_{\alpha}(t, u) d t .
$$

For $\alpha=0$, the variable $u$ corresponds to time, and for $\alpha=\pi / 2$, it corresponds to frequency. The transform kernel $K_{\alpha}(t, u)$ is given in (12), shown at the bottom of the next page.

Efficient algorithms for computing the FrFT of discrete signals have been proposed in [50] and [51].

The FrFT $F^{\alpha}$ depends on the parameter $\alpha$ and can be interpreted as a rotation by an angle $\alpha$ in the time-frequency plane.
$F^{\pi / 2}$ corresponds to the classical FT. The angles of successively performed FrFTs simply add up, as do the angles of successive rotations. The FrFT of a signal can also be interpreted as a decomposition of the signal in terms of chirps (signals with linearly varying frequency). This physical interpretation of the FrFT can be exploited for detecting chirplike signals, such as those that are generated by fault harmonics during a speed transient [see (2) and (3)]. In the following, this property will be exploited to characterize, first, a test chirp signal and, second, the LSHst of a faulty machine with broken bars.

\section{A. FrFT of a Linear Chirp}

A synthetic linear chirp, with an initial frequency of $50 \mathrm{~Hz}$ and a sweep rate of $-50 \mathrm{~Hz} / \mathrm{s}$, i.e.,

$$
x(t)=\cos \left(2 \pi 50\left(t-t^{2} / 2\right)\right) .
$$




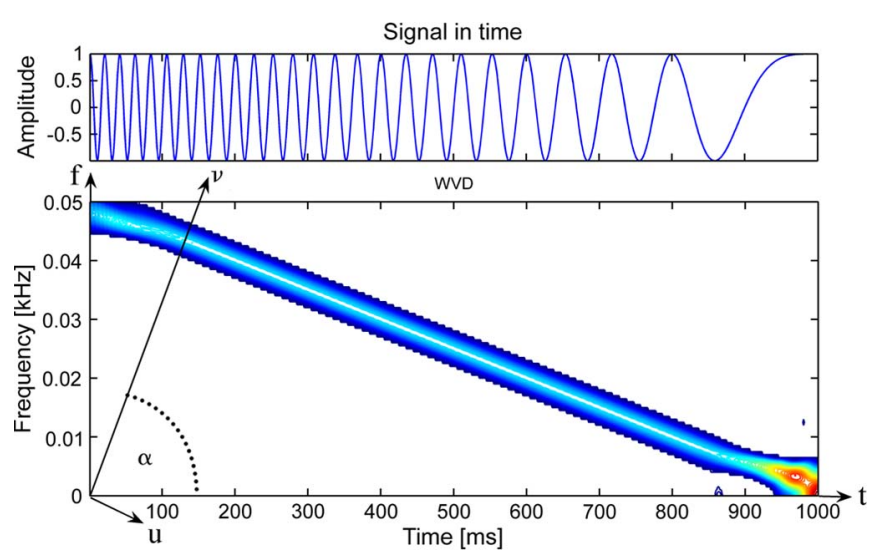

Fig. 8. WVD of a linear chirp.

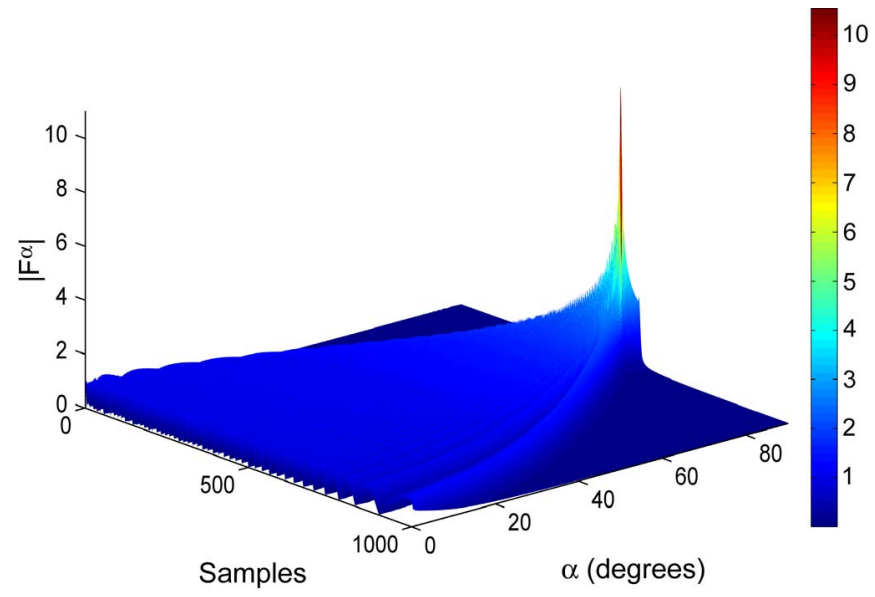

Fig. 9. $\left|F^{\alpha}\right|$ of a linear chirp as a function of the angle $\alpha$ (3-D view).

has been sampled during $1 \mathrm{~s}$ at $1 \mathrm{kHz}$. It is shown in Fig. 8, along with its WVD.

The FrFT of $x(t)$ as a function of the angle $\alpha$, i.e., $F_{x}^{\alpha}(u)$, is the projection of $\operatorname{WVD}(x)$ onto the rotated axis $v$ of Fig. 8. Its module is represented in Fig. 9 as a 3-D view and, in Fig. 10, as a 2-D view, with the amplitudes represented using a color map. For simplicity, the notation that is used to denote the module of $F_{x}^{\alpha}(u)$ in the following figures is $F^{\alpha}$.

Pure harmonic signals become a Dirac's delta function in the classical Fourier domain. On the contrary, Figs. 9 and 10 show how the energy of a linear chirp signal is focused on a different domain $\alpha$. Fig. 11 shows the maximum value of $\left|F_{x}^{\alpha}(u)\right|$ as a function of the parameter $\alpha$. The angle at which the energy of the signal is maximally concentrated is, in this case, $\alpha=87.14^{\circ}$, and this differs from the classical Fourier angle $\left(\alpha=90^{\circ}\right)$.

Three different slices of Fig. 9, corresponding to angle values of $0^{\circ}$ (the time domain), $90^{\circ}$ (the classical Fourier

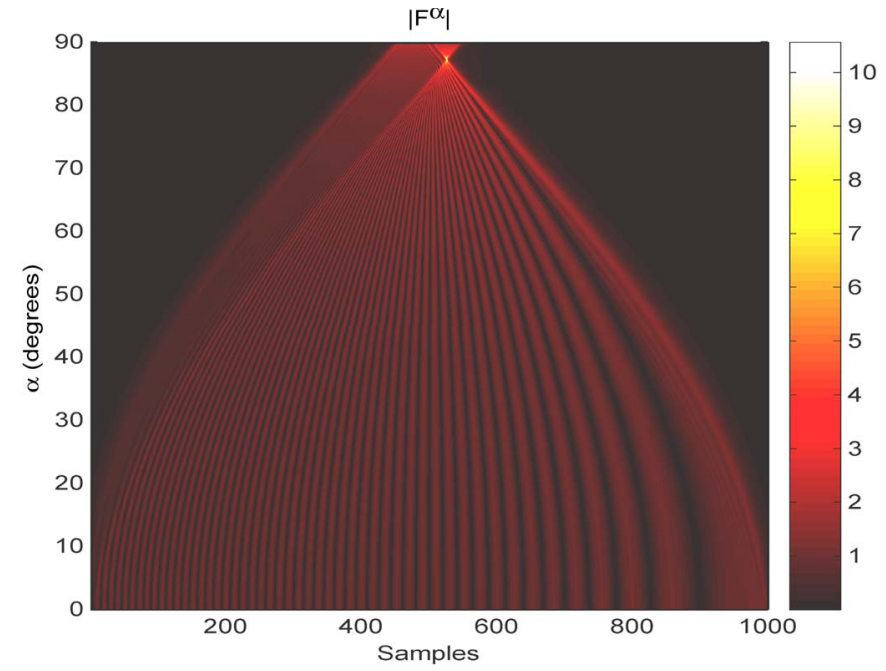

Fig. 10. $\left|F^{\alpha}\right|$ of the linear chirp as a function of the angle $\alpha$ (2-D view).

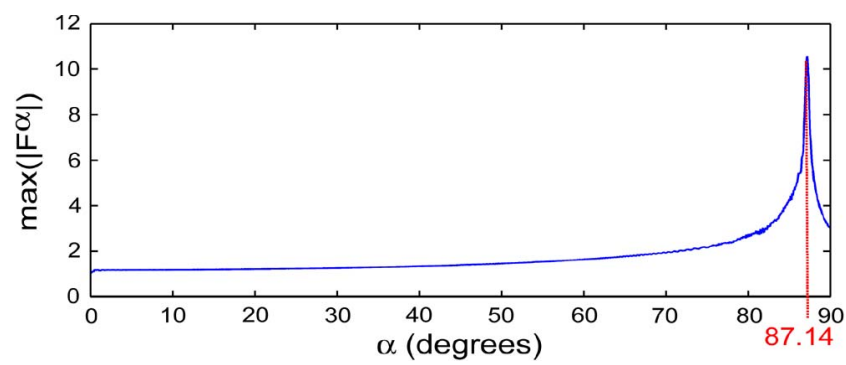

Fig. 11. Maximum value of $\left|F^{\alpha}\right|$ of the linear chirp as a function of the angle $\alpha$.
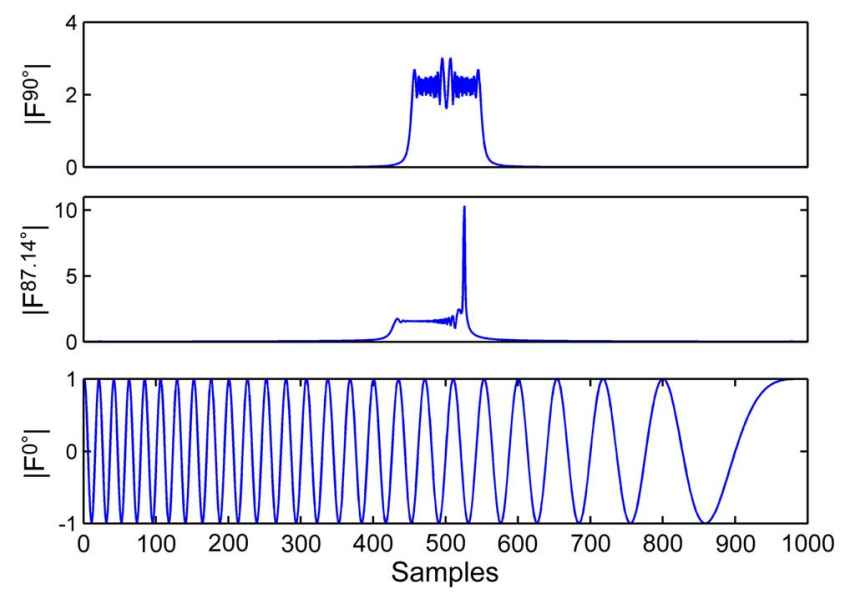

Fig. 12. $\left|F^{\alpha}\right|$ of the linear chirp at $\alpha=0^{\circ}$ (bottom, time domain), $\alpha=$ $87.14^{\circ}$ (middle, highest concentration of the signal's energy around a single value), and $\alpha=90^{\circ}$ (top, classical Fourier domain).

domain), and $87.14^{\circ}$ (the domain where the signal energy is most concentrated around a single value), are represented in Fig. 12.

$$
K_{\alpha}(t, u)= \begin{cases}\delta(t-u), & \text { if } \alpha \text { is a multiple of } 2 \pi \\ \delta(t+u), & \text { if } \alpha+\pi \text { is a multiple of } 2 \pi \\ \sqrt{(1-j \cot \alpha) / 2 \pi} \cdot \exp \left(j \cot (\alpha)\left(t^{2}+u^{2}\right) / 2-j t u \csc (\alpha)\right), & \text { otherwise }\end{cases}
$$




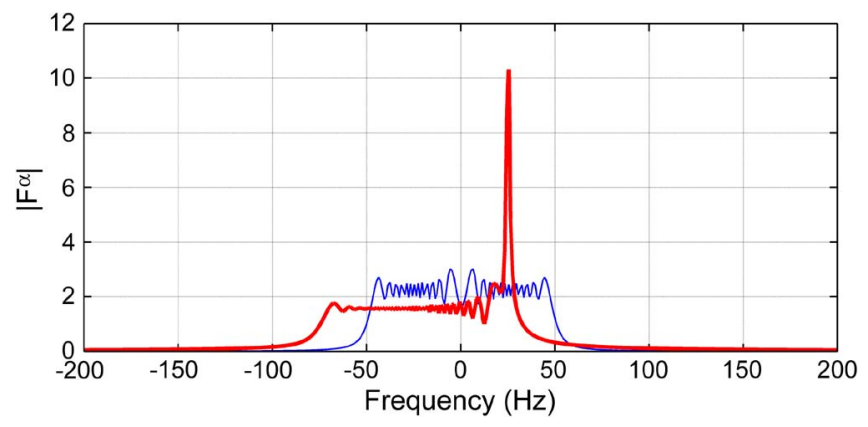

Fig. 13. Comparative plot of $\left|F^{90^{\circ}}\right|$ (thin, blue line, equal to the FT of the signal) and $\left|F^{\alpha}\right|$ with $\alpha=87.14^{\circ}$ (thick, red line).

For an angle $\alpha=87.14^{\circ}, F_{x}^{\alpha}(u)$ has the highest concentration of the signal energy around a single value, and it corresponds to an orientation of the $v$-axis in Fig. 8 perpendicular to the linear chirp signal. In Fig. 13, the spectra in the fractional Fourier domain $F^{87.14^{\circ}}$ and the classical domain $F^{90^{\circ}}$ are plotted together, and their maximum values are compared.

From Fig. 13, the following conclusion can be established: In the same way that a pure harmonic signal in the time domain becomes a delta function in the Fourier domain, a linear chirp signal becomes a delta function in a fractional $F^{\alpha o p t}$ domain. A generic linear chirp signal has the expression

$$
u(t)=\exp \left(j 2 \pi\left(a t+\frac{b t^{2}}{2}\right)\right)
$$

where $a$ represents the initial frequency, and $b$ is the variation rate of frequency (the chirp rate). If (14) is sampled at a frequency $f_{s}$, and $N$ samples are obtained, then the angle $\alpha_{\text {opt }}$ of the FrFT domain that transforms the chirp into a delta function is given by [52]

$$
\alpha_{\mathrm{opt}}=\tan ^{-1}\left(-\frac{f_{s}^{2} / N}{b}\right) .
$$

The value of this angle, which corresponds to the vertical plane of Fig. 9 on which the signal energy is most concentrated, depends on the signal frequency, as follows:

$$
\alpha_{\text {opt }} \begin{cases}<90, & \text { linear chirp with decreasing frequency } \\ =90, & \text { signal with constant frequency } \\ >90, & \text { linear chirp with increasing frequency. }\end{cases}
$$

In the case of signal (13), with $f_{s}=1000 \mathrm{~Hz}$ and $N=1000$

$$
\alpha_{\mathrm{opt}}=\tan ^{-1}\left(-\frac{1000^{2} / 1000}{-50}\right)=87.14^{\circ}
$$

which is the angle corresponding to the maximum value obtained in Fig. 11.

\section{B. FrFT of the LSHst}

The FrFT of the synthetic LSHst, as shown in Fig. 4, has been computed as a function of the angle parameter $\alpha$, and its absolute values are shown in Fig. 14.

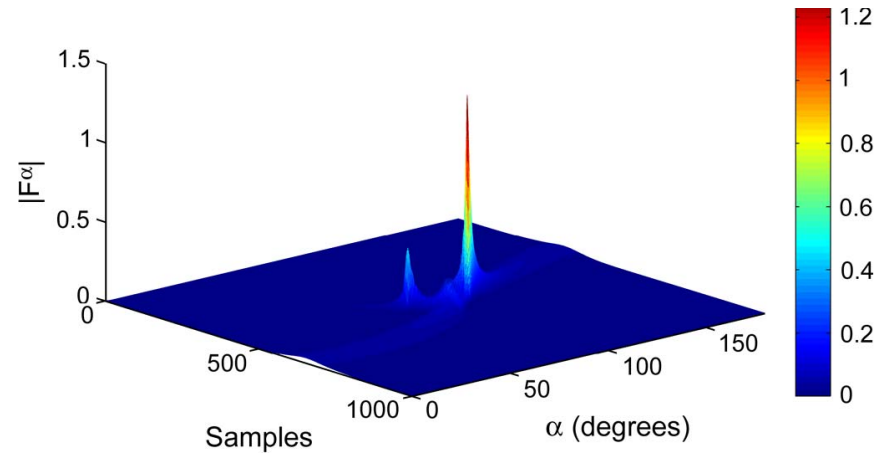

Fig. 14. $\left|F^{\alpha}\right|$ of the LSHst as a function of the angle $\alpha$.

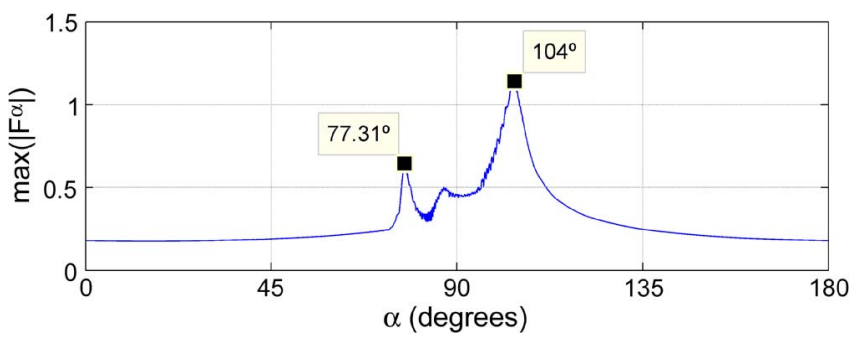

Fig. 15. Maximum value of $\left|F^{\alpha}\right|$ of the LSHst as a function of the angle $\alpha$.

In Fig. 14, two linear chirps are clearly identified through their peaks in the 3-D representation. They correspond to the two branches of the LSHst that are visible in Fig. 6. A simplified plot of the maximum value of $\left|F^{\alpha}\right|$ versus the angle $\alpha$ is shown in Fig. 15.

Two peaks appear in Fig. 15: one with linearly decreasing frequency at $\alpha_{1}=77.31^{\circ}$, and the other peak with an increasing frequency at $\alpha_{2}=104^{\circ}$. This specific pattern, i.e., two chirp components with opposite rates (the FrFT of the first with its maximum value at an angle $\alpha_{1}<90^{\circ}$ and the second at an angle $\alpha_{2}>90^{\circ}$ ), and with the amplitude of the first maximum lower than the amplitude of the second, can be considered as a clear indicator of a broken bar fault.

After a positive identification of this characteristic pattern, the diagnosis can be confirmed by computing the variation rate of the frequency versus the slip, which, for the LSHst [see (3)], must have a constant value of $100 \mathrm{~Hz} / \mathrm{slip}$ unit [see (5)].

By using the first chirp in the LSHst and applying (15), the chirp rate $b$ is found to be equal to

$$
b=-\frac{f_{s}^{2}}{N \tan \left(\alpha_{1}\right)}=\frac{500^{2}}{1000 \cdot \tan (77.31)}=-56.29 \mathrm{~Hz} / \mathrm{s} .
$$

The chirp rate is measured in hertz per second. To assess the presence of a broken bar fault using (5), this value must be converted from hertz per second to hertz per slip unit. To perform this conversion, it is necessary to know the seconds/slip unit ratio. Using the first chirp component, which varies from a slip value of 1 to 0.5 during the startup transient, the average value of this ratio can approximately be obtained using the time at which a slip value $s=0.5$ is reached (the time at which the motor reaches half of its synchronous speed). From Fig. 4 (vertical line), it can be seen that the first chirp component of 


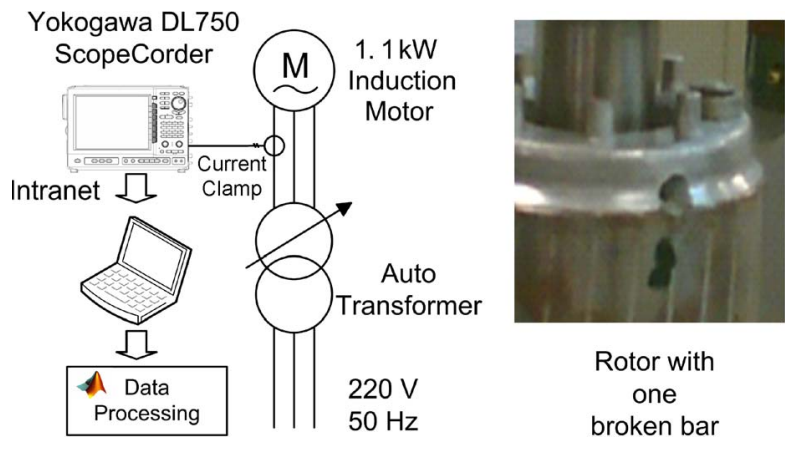

Fig. 16. (Left) Experimental setup and (right) motor with a broken bar used for the validation of the proposed methodology.
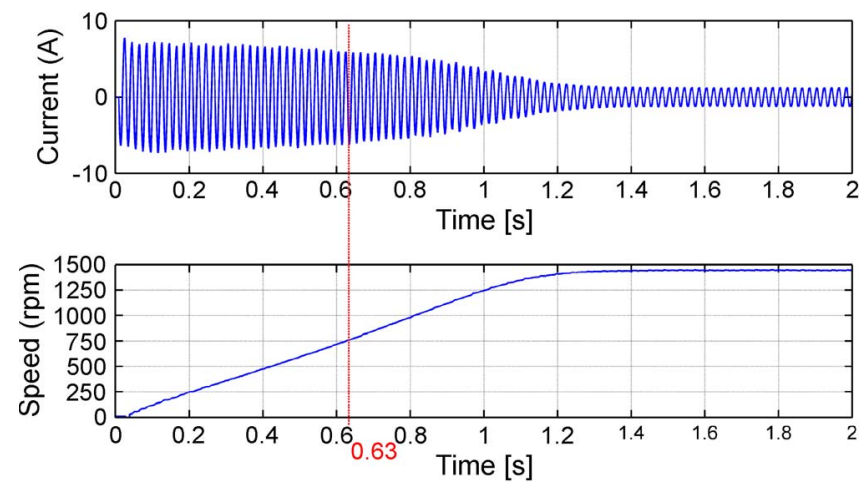

Fig. 17. (Top) Current and (bottom) speed of the experimental motor with a broken bar during the startup transient. The vertical line corresponds to the time when the slip $s=0.5$ is reached.

the LSHst changes from a slip value of 1 to 0.5 in $0.92 \mathrm{~s}$, and thus, the ratio

$$
\left|\frac{\Delta f_{\mathrm{LSH}}}{\Delta s}\right|=\left|b \frac{0.92}{0.5}\right|=56.29 \frac{0.92}{0.5}=103.58 \mathrm{~Hz} / \mathrm{slip} \text { unit }
$$

gives the average variation rate of the LSHst frequency versus the slip in the appropriate units. This value is very close to the theoretical value, i.e., $2 f_{1}=100$ [see (5)], which confirms that this pattern corresponds to a broken bar fault.

\section{EXPERIMENTAL VALIDATION}

The proposed method has been applied to the analysis of a $1.1-\mathrm{kW} 50-\mathrm{Hz}$ induction motor, whose data are given in the Appendix. The test equipment, which is displayed in Fig. 16, consists of a current transformer, a Yokogawa DL750 oscilloscope, and a personal computer connected via an Intranet network.

Tests have been carried out under two different conditions: healthy state and faulty conditions-in which a single bar was broken by drilling a hole. In both cases, the startup current has been recorded for $2 \mathrm{~s}$ using a sampling frequency of $1 \mathrm{kHz}$.

\section{A. Analysis via the FrFT of a Motor With One Broken Bar}

Fig. 17 shows the current of the motor with a broken bar during a startup transient. The motor is unloaded and has been fed with a reduced voltage of $160 \mathrm{~V}$ to achieve a longer startup transient.

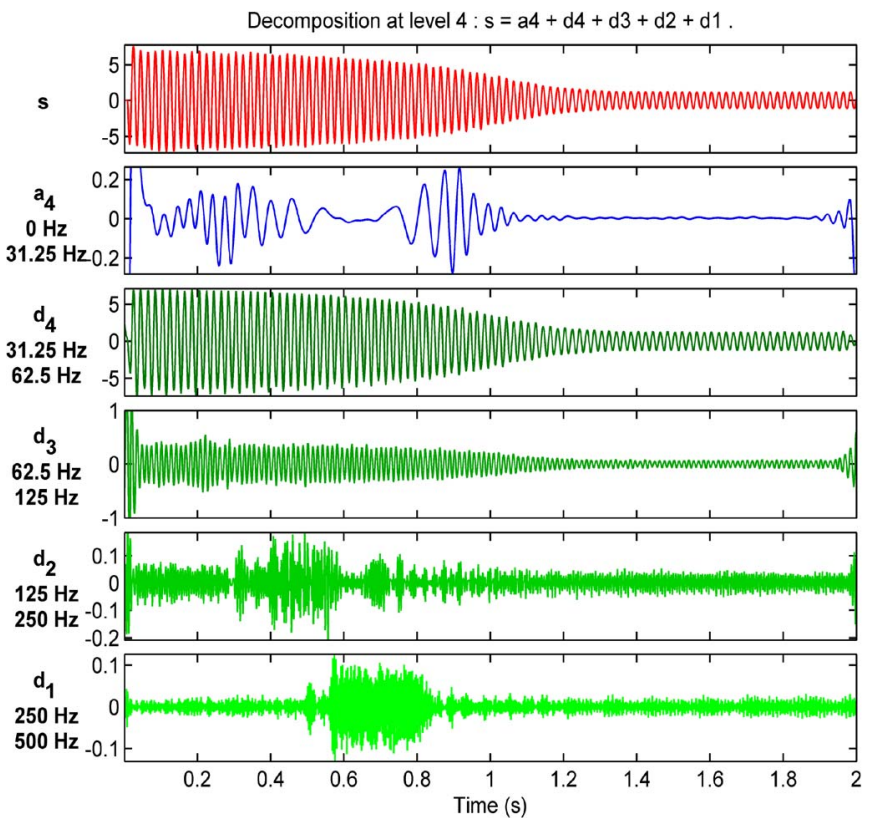

Fig. 18. DWT decomposition of the (top) motor current using a dmeyer mother wavelet. The LSHst is contained in level a4.

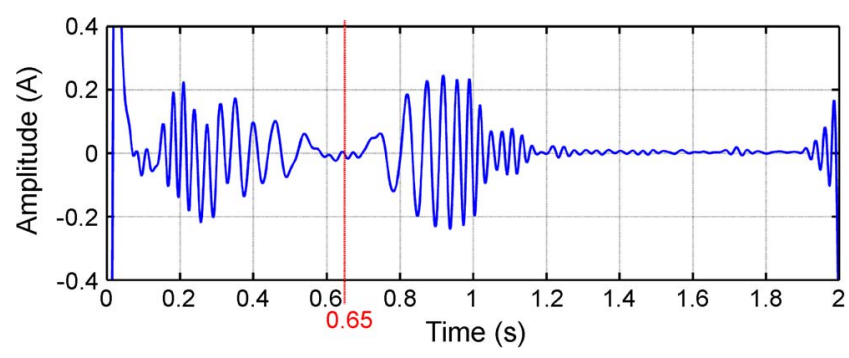

Fig. 19. LSHst of the motor with a broken bar extracted using the approximation signal of the DWT of the motor current. The vertical line marks the estimated time when the motor reaches a slip $s=0.5$.

The proposed method cannot directly be applied to the line current, and the LSHst must first be extracted before performing its analysis via the FrFT. The DWT, whose use as a tool for extracting the harmonics of the current in the transient state has been proposed in [26] and [40], is used in the proposed method to extract the LSHst. The DWT of the experimental motor current has been performed using a dmeyer wavelet with four decomposition levels (see Fig. 18). The number of decomposition levels $n_{f}$ depends on the sampling frequency $f_{s}(1000 \mathrm{~Hz})$. It is calculated as explained in [40], with the condition that the upper limit of the frequency interval of the approximation signal $a_{n f}$ must be lower than the supply frequency $f_{1}(50 \mathrm{~Hz})$. Therefore

$$
n_{f}=\text { Integer }\left[\frac{\log \left(f_{s} / f_{1}\right)}{\log (2)}\right]=\text { Integer }\left[\frac{\log (1000 / 50)}{\log (2)}\right]=4 .
$$

Fig. 19 shows the approximation signal with level 4 of the previous wavelet decomposition; this signal will be used as the experimental LSHst of the faulty machine to validate the proposed approach. 


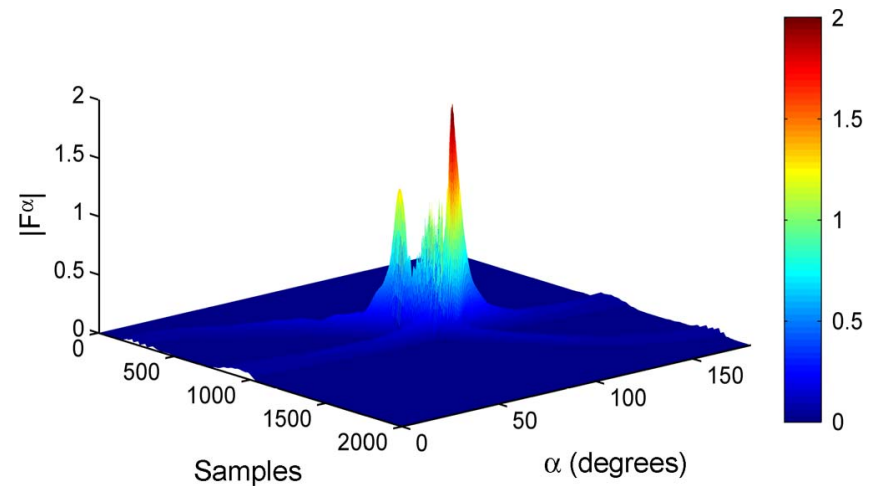

Fig. 20. $\left|F^{\alpha}\right|$ of the experimental LSHst of the motor with a broken bar as a function of the angle $\alpha$.

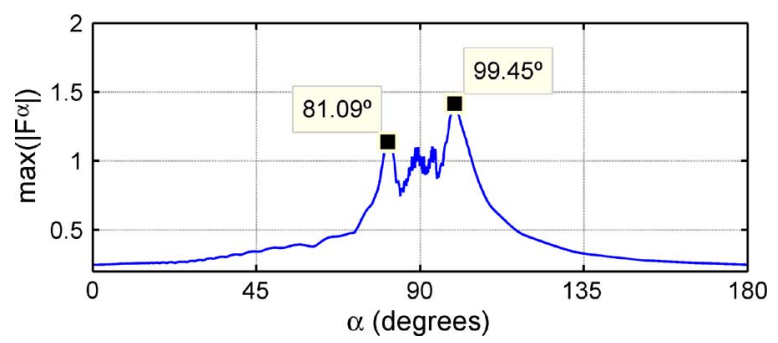

Fig. 21. Maximum value of $\left|F^{\alpha}\right|$ of the experimental LSHst of the faulty motor as a function of the angle $\alpha$.

The FrFT of the experimental LSHst, as shown in Fig. 19, has been computed as a function of the angle parameter $\alpha$, and its absolute values are shown in Fig. 20.

In Fig. 20, the two linear chirp components of the LSHst are clearly identified by their respective peaks in the 3-D representation. A simplified plot of the maximum value of $\left|F^{\alpha}\right|$ versus the angle $\alpha$ is shown in Fig. 21.

In this motor, the characteristic pattern of a bar breakage appears: two chirps with opposite chirp rates. This diagnosis can be confirmed by computing the variation rate of the frequency versus the slip, i.e., $2 f_{1}=100$ [see (5)]. Using the first of the two chirps, with an angle $\alpha_{1}=81.09^{\circ}$, and applying (15) with $f_{s}=1000$ and $N=2000$, the chirp rate results to

$$
b=-\frac{f_{s}^{2}}{N \tan \left(\alpha_{1}\right)}=\frac{1000^{2}}{2000 \cdot \tan (81.09)}=-78.38 \mathrm{~Hz} / \mathrm{s} .
$$

This component presents a change in slip from 1 to 0.5 in $0.63 \mathrm{~s}$ (see Fig. 17), and thus, the ratio

$$
\left|\frac{\Delta f_{\mathrm{LSH}}}{\Delta s}\right|=\left|b \frac{0.63}{0.5}\right|=78.38 \frac{0.63}{0.5}=98.76 \mathrm{~Hz} / \mathrm{slip} \text { unit }
$$

gives the average variation rate of the experimental LSHst frequency in hertz per slip unit. This value is very close to the theoretical value [see (5)], which confirms that this pattern corresponds to a broken bar fault.

In some industrial facilities, the speed of the motor during the startup transient may be unavailable. To measure the motor current, it suffices a single current transformer, which can easily
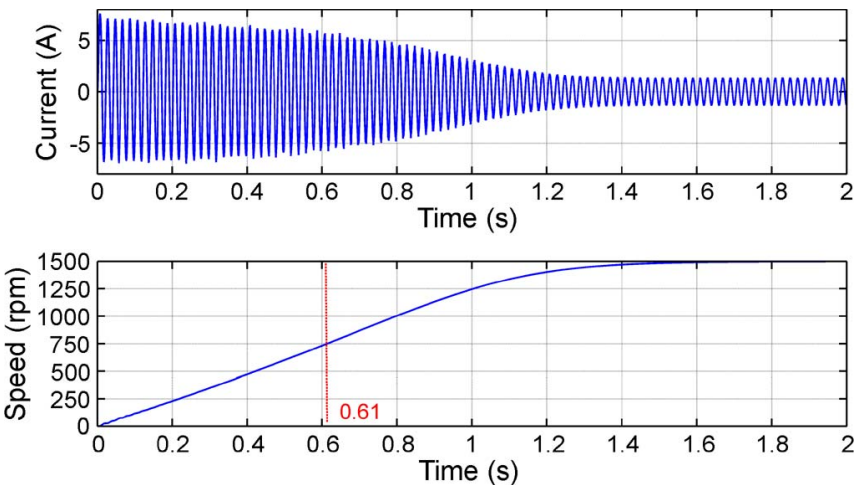

Fig. 22. (Top) Current and (bottom) speed of the experimental healthy motor during the startup transient. The vertical line corresponds to the time when the slip $s=0.5$ is reached.

be inserted in the line; however, to measure the motor speed, it is necessary to connect an encoder to the motor shaft, which is more difficult to implement. Therefore, in some facilities, the motor speed is not measured. In these cases, it is still possible to confirm the diagnosis of a broken bar fault: It suffices to estimate, from the graphical representation of the LSHst, the duration of its first chirp component (which finishes at a slip $s=0.5$, as stated in Section II). In Fig. 19, this time has been estimated as $t=0.65 \mathrm{~s}$ (vertical line), which is slightly different from the measured value. This gives an average variation rate of the LSHst frequency versus the slip of

$$
\left|\frac{\Delta f_{\mathrm{LSH}}}{\Delta s}\right|=\left|b \frac{0.65}{0.5}\right|=78.38 \frac{0.65}{0.5}=101.89 \mathrm{~Hz} / \mathrm{slip} \text { unit. }
$$

This value is again very close to the theoretical value [see (5)], which confirms that the detected pattern corresponds to a broken bar fault.

\section{B. Analysis via the FrFT of a Healthy Motor}

Another motor, in this case a healthy motor, operating under the same conditions as the faulty motor has also been analyzed using the FrFT. Fig. 22 shows the current of the healthy motor during the startup transient, which is sampled for $2 \mathrm{~s}$ at $1 \mathrm{kHz}$.

The LSHst harmonic has been extracted using the approximation signal of the DWT of the current signal, with a dmeyer mother wavelet and four levels of decomposition, as shown in Fig. 23. The approximation signal with level 4 of the previous wavelet decomposition, which should contain the expected LSHst, is shown in Fig. 24.

This signal is now analyzed with the FrFT to detect the characteristic chirp components of the LSHst in a motor with broken bars. Fig. 25 shows the magnitude of the signal's FrFT as a function of the angle parameter. A simplified plot of the maximum value of $\left|F^{\alpha}\right|$ versus the angle $\alpha$ is shown in Fig. 26.

In Figs. 25 and 26, a single peak appears at an angle $\alpha_{1}=$ $92.79^{\circ}$. This pattern does not correspond to the characteristic two-chirp pattern of the broken bar fault. In fact, it is the energy of the electromagnetic transient at the beginning of the startup 


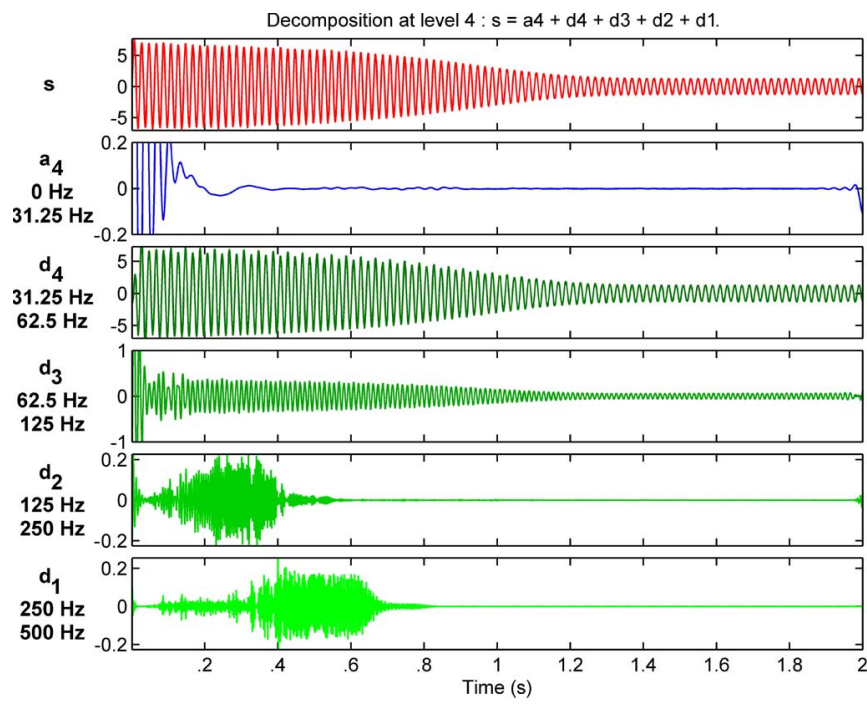

Fig. 23. DWT decomposition of the (top) healthy motor current using a dmeyer mother wavelet.

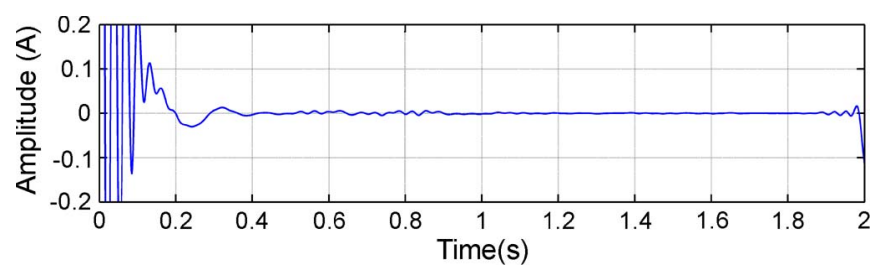

Fig. 24. LSHst of the healthy motor extracted using the approximation signal of the DWT of the motor current.

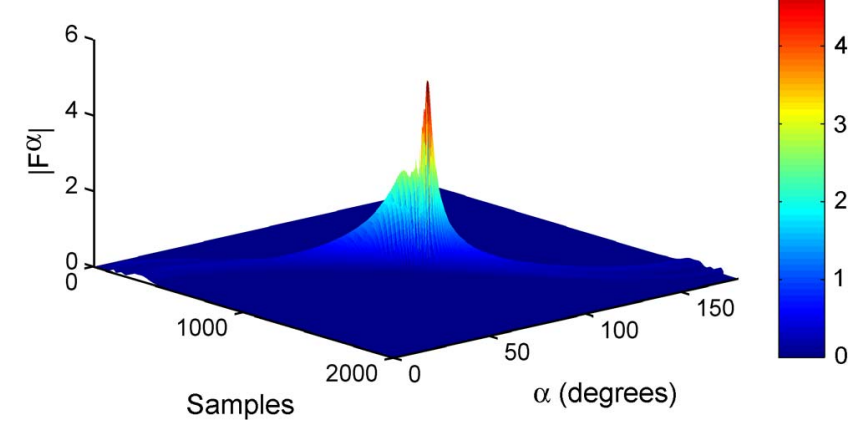

Fig. 25. $\left|F^{\alpha}\right|$ of the experimental LSHst of the healthy motor as a function of $\alpha$.

that is being detected in both figures. Moreover, the detected transient has a chirp rate of

$$
b=-\frac{f_{s}^{2}}{N \tan \left(\alpha_{1}\right)}=\frac{1000^{2}}{2000 \cdot \tan (92.79)}=-24.37 \mathrm{~Hz} / \mathrm{s} .
$$

This component presents a change in slip from 1 to 0.5 in $0.61 \mathrm{~s}$ (see Fig. 22), and thus, the ratio

$$
\left|\frac{\Delta f_{\mathrm{LSH}}}{\Delta s}\right|=\left|b \frac{0.61}{0.5}\right|=24.37 \frac{0.61}{0.5}=29.72 \mathrm{~Hz} / \mathrm{slip} \text { unit }
$$

gives the average variation rate of the experimental LSHst frequency in hertz per slip unit. This value is very different to

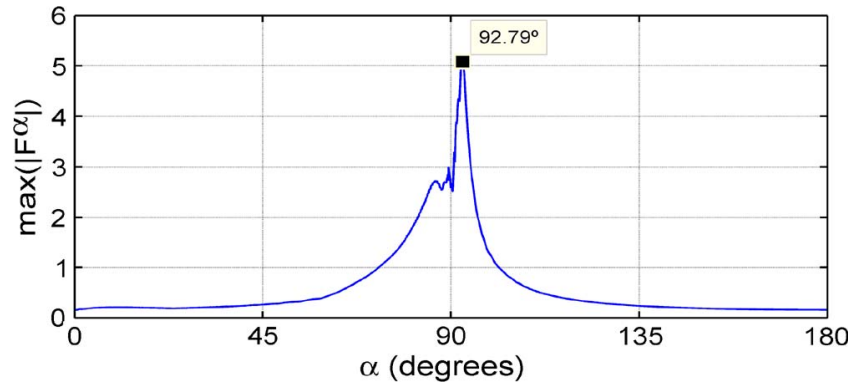

Fig. 26. Maximum value of $\left|F^{\alpha}\right|$ of the experimental LSHst of the healthy motor as a function of the angle $\alpha$.

the theoretical value [see (5)], which confirms that the detected signal does not correspond to a broken bar fault.

\section{CONCLUSION}

In this paper, the FrFT $F^{\alpha}$ has been presented as the extension of the traditional FT for performing transient MCSA. One of the main difficulties that arise in the diagnosis of induction motor faults in TMCSA is the difficulty of generating fault indexes from the time-frequency representation of the motor current. In the permanent regime, these indexes are mainly based on the presence of characteristic peaks in the modulus of the Fourier spectrum of the current. The height of these peaks can even be used to evaluate the severity of the fault. This technique cannot be extended to the transient regime because the signals are not stationary. For example, during a startup transient, the frequency of the LSHst exhibits a linear variation with the slip. In the proposed method, it is precisely the slope of the curve frequency-slip that is measured with the FrFT, and the result is presented in a way that is very similar to the classical Fourier spectrum: The measured slope appears as a single peak in the fractional Fourier spectrum, and each type of fault generates a specific unique peak in this spectrum. Therefore, this method can complement the classical MCSA method in cases when the diagnostic is not clear (due to the presence of load oscillations, etc.).

The classical FT can be considered a particular case of $F^{\alpha}$ for a parameter $\alpha=\pi / 2$. Two physical properties of this transform have been presented. The first corresponds to the rotation of the signal in the frequency-time domain. It has the ability to represent a linear chirp signal as a Dirac's delta in the frequency domain. The second is represented by the faultinduced oscillations of the stator current, which evolve as linear chirps during speed transients. This property makes the FrFT a suitable tool for transient MCSA. The conditioning of the signal before applying the FrFT has been made with a DWT filtering stage. As an application of the proposed technique, the detection of rotor bar breakages has been validated via experimental diagnosis of faulty and healthy $1.1-\mathrm{kW}$ motors.

On the other hand, one of the main limitations of the proposed method is the lack of correlation between the severity of the fault and the height of the peaks in the fractional Fourier spectrum. This is currently a work in progress, and extensive experiments are being done with motors with several broken bars. In addition, this method can be applied to detect other 
faults such as eccentricity, defective bearings, etc. In this case, the performance of the method under combined faults has to be evaluated.

Another limitation of the method is the need of a minimum length for the startup. This is necessary to avoid both the influence of the initial electromagnetic transient, taking place after the connection of every machine, and the border effects, which, in the earlier stage of the startup transient, can completely mask the sideband component. As a guideline, with starting times above $0.5 \mathrm{~s}$, the method is suitable.

\section{APPENDIX}

Machine Parameters: A three-phase induction motor of $1.1 \mathrm{~kW}, 50 \mathrm{~Hz}, 230 / 400 \mathrm{~V}, 2.7 / 4.6 \mathrm{~A}, 1410 \mathrm{r} / \mathrm{min}$, and $\cos \varphi=0.8$.

\section{REFERENCES}

[1] M. E. H. Benbouzid and G. B. Kliman, "What stator current processingbased technique to use for induction motor rotor faults diagnosis?" IEEE Trans. Energy Convers., vol. 18, no. 2, pp. 238-244, Jun. 2003.

[2] H. Henao, H. Razik, and G. A. Capolino, "Analytical approach of the stator current frequency harmonics computation for detection of induction machine rotor faults," IEEE Trans. Ind. Appl., vol. 41, no. 3, pp. 801-807, May/Jun. 2005.

[3] J. H. Jung, J. J. Lee, and B. H. Kwon, "Online diagnosis of induction motors using MCSA," IEEE Trans. Ind. Electron., vol. 53, no. 6, pp. 18421852, Dec. 2006.

[4] M. E. H. Benbouzid, M. Vieira, and C. Theys, "Induction motors' faults detection and localization using stator current advanced signal processing techniques," IEEE Trans. Power Electron., vol. 14, no. 1, pp. 14-22, Jan. 1999.

[5] A. Bellini, F. Filippetti, D. Casadei, A. Yazidi, and G. A. Capolino, "Monitoring of induction machines currents by high frequency resolution analysis," in Conf. Rec. 41st IEEE IAS Annu. Meeting, Tampa, FL, Oct. 8-12, 2006, pp. 2320-2325.

[6] R. Puche-Panadero, M. Pineda-Sanchez, M. Riera-Guasp, J. Roger-Folch, E. Hurtado-Perez, and J. Perez-Cruz, "Improved resolution of the MCSA method via Hilbert transform, enabling the diagnosis of rotor asymmetries at very low slip," IEEE Trans. Energy Convers., vol. 24, no. 1, pp. 52-59, Mar. 2009

[7] A. Bellini, F. Filippetti, G. Franceschini, C. Tassoni, and G. B. Kliman, "Quantitative evaluation of induction motor broken bars by means of electrical signature analysis," IEEE Trans. Ind. Appl., vol. 37, no. 5, pp. 1248-1255, Sep./Oct. 2001.

[8] S. H. Kia, H. Henao, and G. A. Capolino, "A high-resolution frequency estimation method for three-phase induction machine fault detection," IEEE Trans. Ind. Electron., vol. 54, no. 4, pp. 2305-2314, Aug. 2007.

[9] M. C. Ian and R. Wendell, "Using current signature analysis technology to reliably detect cage winding defects in squirrel-cage induction motors," IEEE Trans. Ind. Appl., vol. 43, no. 2, pp. 422-428, Mar./Apr. 2007.

[10] J. D. J. Rangel-Magdaleno, R. D. J. Romero-Troncoso, R. A. Osornio-Rios, E. Cabal-Yepez, and L. M. Contreras-Medina, "Novel methodology for online half-broken-bar detection on induction motors," IEEE Trans. Instrum. Meas., vol. 58, no. 5, pp. 1690-1698, May 2009.

[11] A. Bellini, A. Yazidi, F. Filippetti, C. Rossi, and G. A. Capolino, "High frequency resolution techniques for rotor fault detection of induction machines," IEEE Trans. Ind. Electron., vol. 55, no. 12, pp. 4200-4209, Dec. 2008.

[12] A. Bellini, G. Franceschini, and C. Tassoni, "Monitoring of induction machines by maximum covariance method for frequency tracking," IEEE Trans. Ind. Appl., vol. 42, no. 1, pp. 69-78, Jan./Feb. 2006.

[13] A. Bellini, F. Filippetti, C. Tassoni, and G. A. Capolino, "Advances in diagnostic techniques for induction machines," IEEE Trans. Ind. Electron., vol. 55, no. 12, pp. 4109-4126, Dec. 2008.

[14] A. Bellini, F. Filippetti, G. Franceschini, C. Tassoni, R. Passaglia, M. Saottini, G. Tontini, M. Giovannini, and A. Rossi, "On-field experience with online diagnosis of large induction motors cage failures using MCSA," IEEE Trans. Ind. Appl., vol. 38, no. 4, pp. 1045-1053, Jul./Aug. 2002.
[15] M. A. S. K. Khan, T. S. Radwan, and M. A. Rahman, "Real-time implementation of wavelet packet transform-based diagnosis and protection of three-phase induction motors," IEEE Trans. Energy Convers., vol. 22, no. 3, pp. 647-655, Sep. 2007.

[16] S. Rajagopalan, J. M. Aller, J. A. Restrepo, T. G. Habetler, and R. G. Harley, "Analytic-wavelet-ridge-based detection of dynamic eccentricity in brushless direct current (BLDC) motors functioning under dynamic operating conditions," IEEE Trans. Ind. Electron., vol. 54, no. 3, pp. 1410-1419, Jun. 2007.

[17] M. Aminian and F. Aminian, "A modular fault-diagnostic system for analog electronic circuits using neural networks with wavelet transform as a preprocessor," IEEE Trans. Instrum. Meas., vol. 56, no. 5, pp. 15461554, Oct. 2007.

[18] D. Giaouris, J. W. Finch, O. C. Ferreira, R. M. Kennel, and G. M. El-Murr, "Wavelet denoising for electric drives," IEEE Trans. Ind. Electron., vol. 55, no. 2, pp. 543-550, Feb. 2008.

[19] P. Flandrin, G. Rilling, and P. Goncalves, "Empirical mode decomposition as a filter bank," IEEE Signal Process. Lett., vol. 11, no. 2, pp. 112-114, Feb. 2004.

[20] R. Yan and R. X. Gao, "Hilbert-Huang transform-based vibration signal analysis for machine health monitoring," IEEE Trans. Instrum. Meas., vol. 55, no. 6, pp. 2320-2329, Dec. 2006.

[21] A. O. Boudraa and J. C. Cexus, "EMD-based signal filtering," IEEE Trans. Instrum. Meas., vol. 56, no. 6, pp. 2196-2202, Dec. 2007.

[22] H. Douglas, P. Pillay, and A. K. Ziarani, "Broken rotor bar detection in induction machines with transient operating speeds," IEEE Trans. Energy Convers., vol. 20, no. 1, pp. 135-141, Mar. 2005.

[23] B. Yazici and G. B. Kliman, "An adaptive statistical time-frequency method for detection of broken bars and bearing faults in motors using stator current," IEEE Trans. Ind. Appl., vol. 35, no. 2, pp. 442-452, Mar./Apr. 1999.

[24] A. Ordaz-Moreno, R. de Jesus Romero-Troncoso, J. A. Vite-Frias, J. R. Rivera-Gillen, and A. Garcia-Perez, "Automatic online diagnosis algorithm for broken-bar detection on induction motors based on discrete wavelet transform for FPGA implementation," IEEE Trans. Ind. Electron., vol. 55, no. 5, pp. 2193-2202, May 2008.

[25] J. Antonino-Daviu, M. Riera-Guasp, J. Roger-Folch, F. MartínezGiménez, and A. Peris, "Application and optimization of the discrete wavelet transform for the detection of broken rotor bars in induction machines," Appl. Comput. Harmon. Anal., vol. 21, no. 2, pp. 268-279, 2006.

[26] J. A. Antonino-Daviu, M. Riera-Guasp, J. R. Folch, and M. Pilar Molina Palomares, "Validation of a new method for the diagnosis of rotor bar failures via wavelet transform in industrial induction machines," IEEE Trans. Ind. Appl., vol. 42, no. 4, pp. 990-996, Jul./Aug. 2006.

[27] P. H. Cox and A. A. de Carvalho, "Discrete wavelet transform signal analyzer," IEEE Trans. Instrum. Meas., vol. 56, no. 5, pp. 1640-1647, Oct. 2007.

[28] J. Cusido, L. Romeral, J. A. Ortega, J. A. Rosero, and A. Garcia Espinosa, "Fault detection in induction machines using power spectral density in wavelet decomposition," IEEE Trans. Ind. Electron., vol. 55, no. 2, pp. 633-643, Feb. 2008.

[29] F. Briz, M. W. Degner, P. Garcia, and D. Bragado, "Broken rotor bar detection in line-fed induction machines using complex wavelet analysis of startup transients," IEEE Trans. Ind. Appl., vol. 44, no. 3, pp. 760-768, May/Jun. 2008.

[30] P. Clarkson and P. S. Wright, "A wavelet-based method of measuring fluctuating harmonics for determining the filter time constant of IEC standard harmonic analyzers," IEEE Trans. Instrum. Meas., vol. 54, no. 2, pp. 488-491, Apr. 2005.

[31] L. Peretto, R. Sasdelli, and R. Tinarelli, "On uncertainty in wavelet-based signal analysis," IEEE Trans. Instrum. Meas., vol. 54, no. 4, pp. $1593-$ 1599, Aug. 2005

[32] Z. Li and M. J. Crocker, "A study of joint time-frequency analysis-based modal analysis," IEEE Trans. Instrum. Meas., vol. 55, no. 6, pp. 23352342, Dec. 2006.

[33] F. Ponci, A. Monti, L. Cristaldi, and M. A. L. M. Lazzaroni, "Diagnostic of a faulty induction motor drive via wavelet decomposition," IEEE Trans. Instrum. Meas., vol. 56, no. 6, pp. 2606-2615, Dec. 2007.

[34] J. Liu, W. Wang, and F. Golnaraghi, "An extended wavelet spectrum for bearing fault diagnostics," IEEE Trans. Instrum. Meas., vol. 57, no. 12, pp. 2801-2812, Dec. 2008.

[35] M. Blodt, D. Bonacci, J. Regnier, M. Chabert, and J. Faucher, "On-line monitoring of mechanical faults in variable-speed induction motor drives using the Wigner distribution," IEEE Trans. Ind. Electron., vol. 55, no. 2, pp. 522-533, Feb. 2008. 
[36] S. Rajagopalan, J. M. Aller, J. A. Restrepo, T. G. Habetler, and R. G. Harley, "Detection of rotor faults in brushless DC motors operating under nonstationary conditions," IEEE Trans. Ind. Appl., vol. 42, no. 6, pp. 1464-1477, Nov./Dec. 2006.

[37] Z. Leonowicz, T. Lobos, and T. Sikorski, "Time-frequency analysis of complex space phasor in power electronics," IEEE Trans. Instrum. Meas., vol. 56, no. 6, pp. 2395-2403, Dec. 2007.

[38] W. Changting and R. X. Gao, "Wavelet transform with spectral postprocessing for enhanced feature extraction," IEEE Trans. Instrum. Meas., vol. 52, no. 4, pp. 1296-1301, Aug. 2003.

[39] A. K. Ziarani, A. Konrad, and A. N. Sinclair, "A novel time-domain method of analysis of pulsed sine wave signals," IEEE Trans. Instrum. Meas., vol. 52, no. 3, pp. 809-814, Jun. 2003.

[40] M. Riera-Guasp, J. A. Antonino-Daviu, J. Roger-Folch, and M. P. Molina Palomares, "The use of the wavelet approximation signal as a tool for the diagnosis of rotor bar failures," IEEE Trans. Ind. Appl., vol. 44, no. 3, pp. 716-726, May/Jun. 2008.

[41] V. Namias, "The fractional order Fourier transform and its application to quantum mechanics," IMA J. Appl. Math., vol. 25, no. 3, pp. 241-265, 1980.

[42] A. C. McBride and F. H. Kerr, "On Namias's fractional Fourier transforms," IMA J. Appl. Math., vol. 39, no. 2, pp. 159-175, 1987.

[43] A. I. Zayed, "On the relationship between the Fourier and fractional Fourier transforms," IEEE Signal Process. Lett., vol. 3, no. 12, pp. 310311, Dec. 1996.

[44] M. Martone, W. J. C. Inc, and C. A. San Jose, "A multicarrier system based on the fractional Fourier transform for time-frequency-selective channels," IEEE Trans. Commun., vol. 49, no. 6, pp. 1011-1020, Jun. 2001.

[45] R. G. Dorsch, A. W. Lohmann, Y. Bitran, D. Mendlovic, and H. M. Ozaktas, "Chirp filtering in the fractional Fourier domain," Appl. Opt., vol. 33, no. 32, pp. 7599-7602, Nov. 1994.

[46] S. Hong-Bo, L. Guo-Sui, G. Hong, and S. Wei-Min, "Application of the fractional Fourier transform to moving target detection in airborne SAR," IEEE Trans. Aerosp. Electron. Syst., vol. 38, no. 4, pp. 1416-1424, Oct. 2002.

[47] M. F. Erden, M. A. Kutay, and H. M. Ozaktas, "Repeated filtering in consecutive fractional Fourier domains and its application to signal restoration," IEEE Trans. Signal Process., vol. 47, no. 5, pp. 1458-1462, May 1999.

[48] A. W. Lohmann and B. H. Soffer, "Relationships between the Radon-Wigner and fractional Fourier transforms," J. Opt. Soc. Amer. A, Opt. Image Sci., vol. 11, no. 6, pp. 1798-1801, 1994.

[49] L. B. Almeida, "The fractional Fourier transform and time-frequency representations," IEEE Trans. Signal Process., vol. 42, no. 11, pp. 30843091, Nov. 1994.

[50] S. C. Pei, M. H. Yeh, and T. L. Luo, "Fractional Fourier series expansion for finite signals and dual extension to discrete-time fractional Fourier transform," IEEE Trans. Signal Process., vol. 47, no. 10, pp. 2883-2888, Oct. 1999.

[51] C. Candan, M. A. Kutay, and H. M. Ozaktas, "The discrete fractional Fourier transform," IEEE Trans. Signal Process., vol. 48, no. 5, pp. 13291337, May 2000.

[52] C. Capus, Y. Rzhanov, and L. Linnett, "The analysis of multiple linear chirp signals," in Proc. IEE Symp. Time-Scale Time-Frequency Anal. Appl., London, U.K., Feb. 2000, pp. 4/1-4/7.

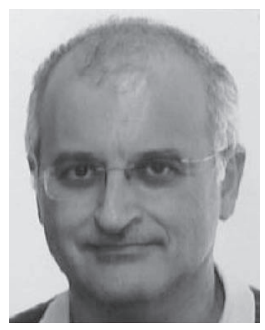

Manuel Pineda-Sanchez (M'02) was born in Albacete, Spain, in 1962. He received the Dipl.Ing. and Dr.Ing. degrees in electrical engineering from the Universidad Politécnica de Valencia, Valencia, Spain, in 1985 and 2004, respectively.

In 1987, he joined the faculty of the Universidad Politécnica de Valencia as an Associate Professor with the Department of Electrical Engineering, in the area of theory and control of electrical machines. His research interests include electrical machines and drives, induction motor diagnostics, numerical simulation of electromagnetic fields, and software development.

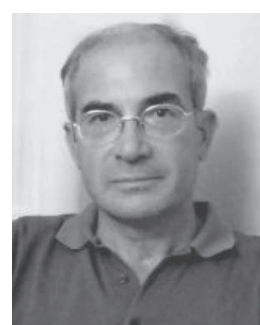

M. Riera-Guasp (M'95) received the M.Sc. degree in industrial engineering and the Ph.D. degree in electrical engineering from the Universidad Politécnica de Valencia, Valencia, Spain, in 1981 and 1987, respectively.

$\mathrm{He}$ is currently an Associate Professor with the Department of Electrical Engineering, Universidad Politécnica de Valencia. His research interests include condition monitoring of electrical machines, applications of the wavelet theory to electrical engineering, and efficiency in electric power

applications

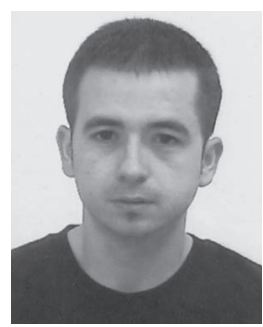

Jose A. Antonino-Daviu (M'04) received the M.Sc. and $\mathrm{Ph} . \mathrm{D}$. degrees in electrical engineering from the Universidad Politécnica de Valencia, Valencia, Spain, in 2000 and 2006, respectively.

$\mathrm{He}$ worked in the private sector, being involved in several international projects. He is currently an Associate Professor with the School of Industrial Engineering, Universidad Politécnica de Valencia, where he develops his docent and research work. His primary research interests include condition monitoring of electric machines, wavelet theory and its application to fault diagnosis, and design and optimization of electrical installations and systems.

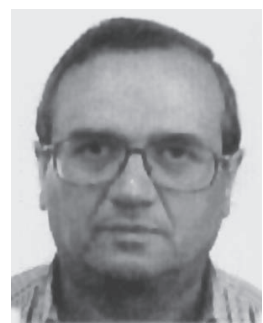

J. Roger-Folch (M'03) received the M.Sc. degree in electrical engineering from the Universidad Politécnica de Cataluña, Barcelona, Spain, in 1970 and the $\mathrm{Ph} . \mathrm{D}$. degree from the Universidad Politécnica de Valencia, Valencia, Spain, in 1980.

From 1971 to 1978 , he worked in the electrical industry as a Project Engineer. Since 1978, he has been with the Universidad Politécnica de Valencia, where he is currently a Professor of electrical installations and machines. His main research areas include numerical methods (FEM and others) applied to the design and maintenance of electrical machines and equipment.

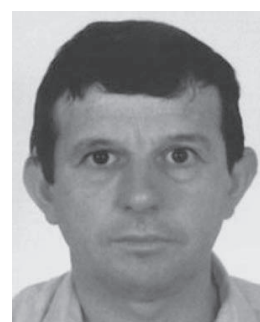

J. Perez-Cruz (M'09) received the M.Sc. degree in electrical engineering and the Ph.D. degree from the Universidad Politécnica de Valencia, Valencia, Spain, in 1997 and 2006, respectively.

From 1970 to 1992, he worked in the electrical industry as an Electrical Technician in the field of industrial systems maintenance and automation. Since 1992, he has been with the Universidad Politécnica de Valencia, where he is currently an Associate Professor of electrical installations and machines. His research interests focus on induction motor diagnostics and maintenance, numerical modeling, and automation of industrial installations.

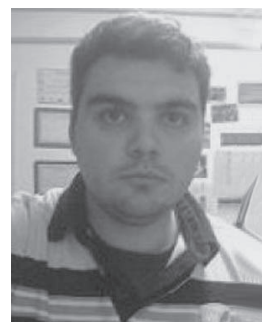

R. Puche-Panadero (M'09) received the M.Sc. degree in automatic and electronic engineering from the Universidad Politécnica de Valencia, Valencia, Spain, in 2003.

From 2003 to 2006, he worked in an Innovate European Automation Project as a developer of the SCADA programs and control panels. Since 2006, he has been with the Universidad Politécnica de Valencia, where he is currently an Assistant Professor of machine control. His research interests focus on induction motor diagnostics and maintenance, numerical modeling, and automation of industrial installations. 